\title{
Corneal evaluation of prospective aphakic wearers of contact lenses
}

\author{
MICHEL GUILLON AND JUDITH A. MORRIS \\ From the Contact Lens Department, Moorfields Eye Hospital, City Road, London EC1V 2PD
}

SUMMARY The corneal response of a group of the affected eyes of prospective monocular aphakic wearers of contact lenses as compared with that of their normal fellow eyes was studied. The results show a reduced corneal sensitivity and endothelial cell density but identical centre corneal thickness and corneal oxygen uptake.

\begin{abstract}
A recent investigation' has shown that the cornea of the aphakic eye swells less than that of the normal fellow eye when fitted with identical hydrophilic lenses. This confirms previous clinical impressions and would suggest that a metabolic difference may exist between the corneas of the normal and the aphakic eye.

The present investigation was therefore devised to assess certain aspects of the basal corneal metabolism of a group of monocular aphakic patients, the fellow normal eye being used as the control.
\end{abstract}

\section{Material and methods}

Corneal physiology was investigated by means of 4 highly sensitive methods. (1) Aesthesiometry. The touch threshold of the central cornea (CTT), which is the inverse of sensitivity, was measured by the Cochet-Bonnet aesthesiometer. (2) Pachometry. A digital pachometer attachment to the slit lamp was used to measure the central corneal thickness. (3) Corneal oxygen uptake. A polarographic method was chosen to measure the corneal oxygen needs. (4) Endothelial photography. The corneal endothelial density was calculated from photographs taken with the Holden-Zantos attachment to the slit-lamp. For each method the usual precautions regarding measurements and calibration have been taken as described in previous publications. ${ }^{23}$

The patients chosen were all monocular aphakes who had been considered suitable for contact lens wear (Table 1). The criteria for selection were: (1) no problems at surgery; (2) good general health; (3) no ocular abnormality of the nonaphakic eye (apart from

Correspondence to Dr M. Guillon. occasional lenticular opacities); (4) no previous surgery on the nonaphakic eye which was used as a control.

To avoid any diurnal variation all the tests were carried out at the same time of the day, and each patient had been awake for more than 2 hours. ${ }^{4}$

\section{Results}

The 4 basic measurements were attempted on all 20 patients. Because of difficulties with patient co-operation endothelial photography and corneal sensitivity determination were possible in only 18 cases and oxygen uptake measurement in 16 cases.

Pachometry results were obtained for all 20 patients.

For each technique the intrinsic values and percentage difference between the aphakic and phakic eyes were recorded:

$$
\% \text { Difference }=\frac{A-P}{\mathrm{P}} \times 100 \% \text {. }
$$

\section{CORNEAL SENSITIVITY}

The central corneal touch threshold (CTT) for the aphakic eyes was significantly higher than for their fellow phakic eyes, $44 \cdot 0 \pm 50 \cdot 5 \mathrm{mg} / \mathrm{mm}^{2}$ (range 12 to $200 \cdot 0 \mathrm{mg} / \mathrm{mm}^{2}$ ) vs. $15 \cdot 8+7 \cdot 2 \mathrm{mg} / \mathrm{mm}^{2}$ (range 12 to 36 $\mathrm{mg} / \mathrm{mm}^{2}$ ). Further the aphakic eyes showed a much larger CTT scatter than the control group, suggesting

Table 1 Summary details of patients

\begin{tabular}{llll}
\hline Age & $\begin{array}{l}\text { Time since } \\
\text { surgery }\end{array}$ & Type of surgery & Aphakic eves \\
\hline $59 \cdot 6 \pm 12 \cdot 0 \mathrm{yr}$ & $55 \pm 82$ weeks & $\begin{array}{l}\text { Intracapsular 14 } \\
\text { Extracapsular 5 }\end{array}$ & $\begin{array}{l}\text { 11. Right } \\
9 \text { Left } \\
\text { Aspiration 1 }\end{array}$ \\
\hline
\end{tabular}




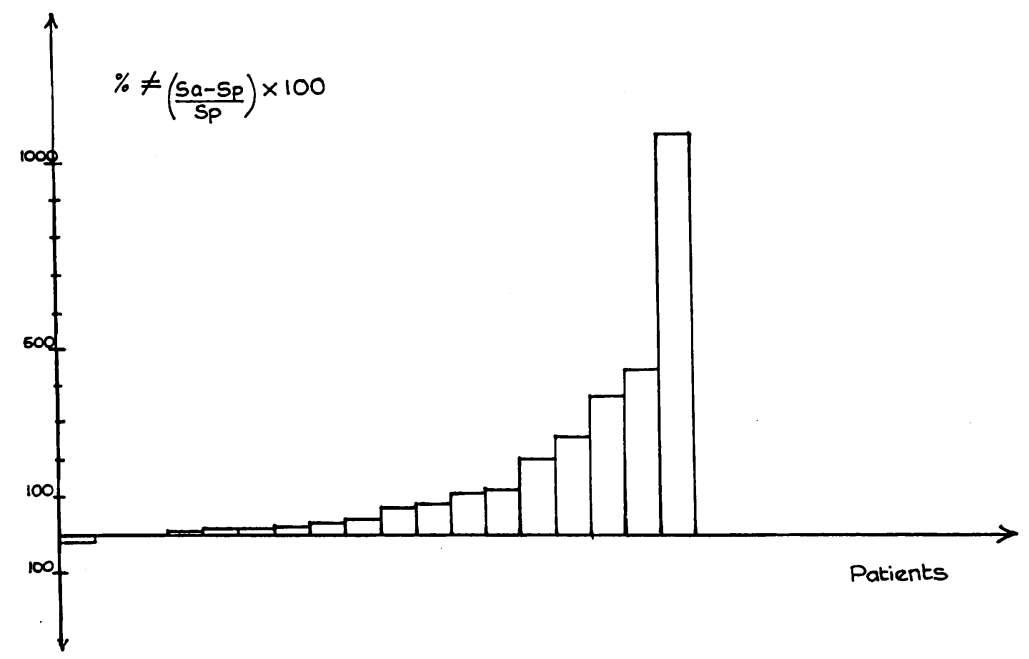

Fig. 1 Histogram showing the percentage difference in CTT between aphakic and phakic eye for each patient.

that the effect of surgical procedure on the corneal sensitivity varied widely. Even when the same surgical procedure was considered (here intracapsular extraction, which was encountered in the largest number of cases), a large variation in results was encountered, $51.0 \pm 54.5 \mathrm{mg} / \mathrm{mm}^{2}$ (range 13.0 to $200 \cdot 0 \mathrm{mg} / \mathrm{mm}^{2}$ ).

The percentage difference for each patient between the aphakic and control eye was $+152.9 \% \pm$ $261 \cdot 2 \%$ (range $-23.9 \%$ to $+1085 \%$ ) and showed that with one exception the aphakic eye was less sensitive than the control eye (Fig. 1).

Because of the large individual variations nonparametric statistics were used (sign test). They showed that the difference was significant at the $1 \%$ level.
CENTRAL CORNEAL THICKNESS

The mean central corneal thickness for the aphakic eye only was marginally higher than for the control group $(0.522 \pm 0.032 \mathrm{~mm}$ (range 0.477 to $0.584 \mathrm{~mm}$ ) vs. $0.518 \pm 0.022 \mathrm{~mm}$ (range 0.462 to $0.561 \mathrm{~mm}$ ). The values obtained being regularly distributed a nonindependent $t$ test was carried out and showed no significant differences between the 2 groups $(t=0 \cdot 626)$.

The percentage differences for each patient were normally distributed (Fig. 2) between $-9.8 \%$ (thicker control eye) and $+7.7 \%$ (thicker aphakic eye), with a mean value $+0 \cdot 72 \% \pm 3 \cdot 74 \%$.

\section{CORNEAL OXYGEN UPTAKE}

The mean corneal oxygen uptake of both groups was identical: $2 \cdot 77 \pm 0.39 \mu \mathrm{l} \mathrm{O}{ }_{2}\left(\mathrm{STP} / \mathrm{cm}^{2} \mathrm{~h}\right)(\mathrm{a}$ range 1.89

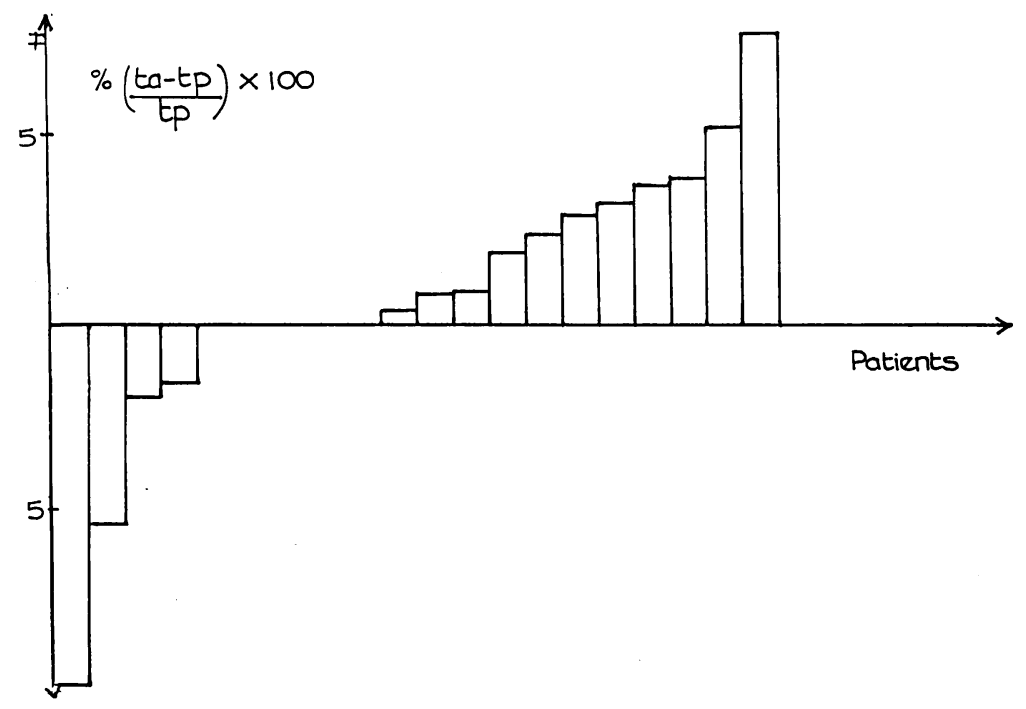

Fig. 2 Histogram showing the percentage difference between the central corneal thickness of aphakic and phakic eye for each patient. 
Fig. 3 Histogram showing the percentage difference in corneal oxygen uptake between aphakic and phakic eye for each patient.

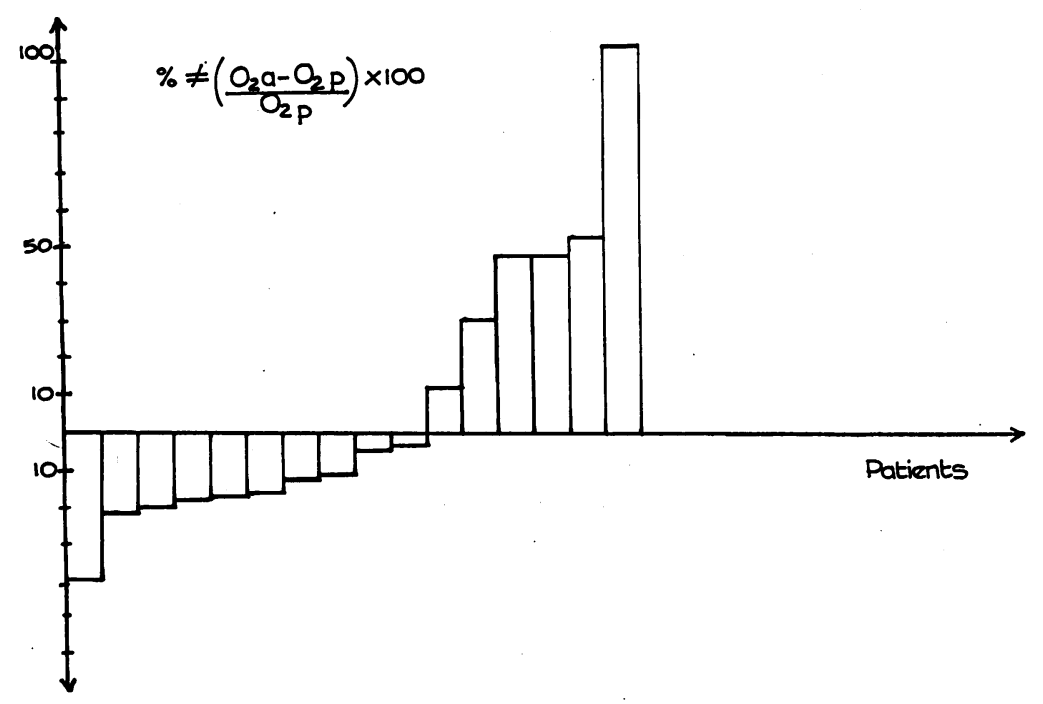

to $3.35 \mu \mathrm{O}_{2}\left(\mathrm{STP} / \mathrm{cm}^{2} \mathrm{~h}\right)$ for the aphakic eyes and $2.77 \pm 0.74 \mu \mathrm{l} \mathrm{O}_{2}$ (STP/cm h (range 1.37 to $3.98 \mu \mathrm{l} \mathrm{O}_{2}$ $(\mathrm{STP}) / \mathrm{cm}^{2} \mathrm{~h}$ ) for the phakic eyes.

The percentage difference was randomly distibuted from $-41.3 \%$ to $+104.4 \%$ (Fig. 3), with a mean of $+8 \cdot 11 \pm 38 \cdot 3 \%$, which is not statistically significant.

\section{ENDOTHELIAL CELL DENSITY}

The mean endothelial cell density for the aphakic eyes was lower than for the phakic eyes: $2867 \pm 442$ cells $/ \mathrm{mm}^{2}$ vs. $3189 \pm 432$ cells $/ \mathrm{mm}^{2}$. Because of the large individual variations nonparametric statistics were used, the sign test being significant at the $1 \%$ level.

The $\%$ difference for each patient was $-9.66 \% \pm$ $15.9 \%$, (range $=+5.6 \%$ to $-5.5 \%$ ), with a pre-

dominantly lower density for the aphakic eye (Fig. 4).

\section{Discussion}

As expected, the corneal sensitivity of the aphakic eye is lower than for the fellow nonoperated eye. Millodot $^{5}$ and Millodot and O'Leary ${ }^{6}$ have shown a correlation between decreased corneal sensitivity and corneal oedema for normal patients. For our group of aphakic corneas the loss of sensitivity cannot be explained in terms of basal metabolic differences. When the CTT is plotted against the corneal oxygen uptake (an indication of the epithelial metabolism) $(r=-0.28)$ and against corneal thickness (an indicator of the stromal metabolism) $(r=-0.33)$ no correlation is detectable.

Fig. 4 Histogram showing the percentage difference in endothelial cell density between aphakic and phakic eye for each patient.

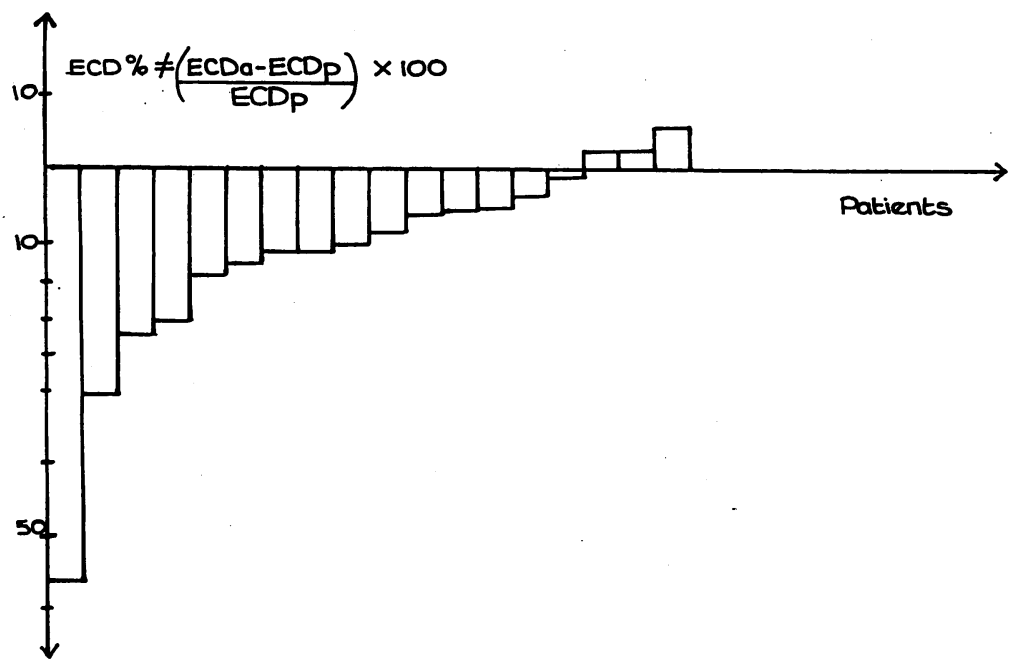


This loss of sensitivity is due in our view to the cutting of the nerves supplying the cornea at surgery. Ruben ${ }^{7}$ suggests that with a $180^{\circ}$ limbal section the sensitivity recovers to a certain extent with time. Our data fail to show any correlation between the time elapsed since surgery and decreased CTT $(r=+0 \cdot 17)$. However, only the central corneal sensitivity was measured, and most of the decrease in sensitivity present would be in the upper zones of the cornea. This does not mean that central recovery is not present, as other parameters may mask this trend: $(a)$ most cases had undergone surgery only recently (within less than a year); (b) the surgical section was variable from one eye to the other. Only a longitudinal study can elucidate these points.

There is no difference in corneal thickness between the aphakic and phakic eyes. This would suggest that if a metabolic difference exists between the 2 groups it does not affect the basal metabolism. Such a finding is not surprising, as the mean endothelial cell loss is lower than $10 \%$, and all corneas show a density superior to 2000 cells $/ \mathrm{mm}^{2}$. Pathological corneas have been shown to maintain normal thickness and transparency with much lower density. ${ }^{8}$

However, Holden et al. ${ }^{1}$ and Guillon and Morris ${ }^{9}$ have shown that surgery has affected the corneal capability to respond to metabolic stress: under reduced level of oxygen the cornea of the aphakic eye swells less than in the fellow eye. Various hypotheses have been formulated to explain this phenomenon but so far with few data to support them: (a) Surgery has increased the endothelial permeability to lactic acid $^{10} ;(b)$ The removal of the crystalline lens has increased the availability of certain metabolites to the endothelium, and this would offset their lack at the corneal front surface. ${ }^{11}$

The corneal oxygen uptake, which is an indication of the epithelial metabolism, is unchanged, showing that the epithelium fully recovers postoperatively except in those instances where endothelial failure causes stromal oedema and secondary bullous changes. $^{3}$

Most of the monocular aphakes will need to be fitted with contact lenses to obtain single binocular vision, and several conclusions can be reached from this work. (a) The cornea of the aphakic eye remains less sensitive than the normal cornea. Hence these patients need to be closely monitored, as they will take longer to detect pain linked with corneal abrasion and/or infection. (b) Despite a basal metabolism similar to that of the normal cornea, the cornea of the aphakic eye will respond better to stress entailed by the wearing of thick lenses with low oxygen transmissibility.

We thank Professor Montague Ruben for encouraging us to carry out this work in the Contact Lens Department at Moorfields Eye Hospital and for reviewing the manuscript.

\section{References}

1 Holden BA, Mertz GW, Guillon M. Corneal swelling response of the aphakic eye. Invest Ophthalmol Visual Sci 1980; 19: 1394-7.

2 Guillon M. Long term effects of hard contact lenses. Contologia 1980; 2: 80-1.

3 Morris JA, Ruben M. Clinical aspects of the measurement of oxygen flux into the cornea. Br J Ophthalmol 1980; 65: 97-100.

4 Mandell RB, Fatt I. Thinning of the human cornea on awakening. Nature $1965 ; 208: 292-3$.

5 Millodot $M$. The influence of pregnancy on the sensitivity of the cornea. Br J Ophthalmol 1977; 61: 646-9.

6 Millodot M, O'Leary DJ. Effect of oxygen deprivation on corneal sensitivity. Acta Ophthalmol (Kbh) 1980; 58: 434-9.

7 Ruben M. Contact Lens Practice. London: Baillière Tindall, 1975: chapter 13.

8 Ruben M, Guillon M. Endothelial Survival in transparent ketatoplasty Trans VIth Congress of the European Society of Ophthalmology, Brighton, April 1980. 1980.

9 Guillon M. Morris J. Differential corneal response to a provocative test in aphakia. J Br Contact Lens Assoc 1981; 4: $162-7$.

10 Fatt I, Chaston J. Reflections on corneal oedema. J Br Contact Lens Assoc 1981; 4: 66-71.

11 Cotlier E. The Lens. Adler's Physiology of the Eye. St Louis: Mosby, 1975: 277. 